\title{
e-Migrinter
}

15 | 2017

Migrinter a trente ans : analyses et portraits

\section{Portrait de Nelly Martin, géomaticienne, bureau}

014

\section{Nelly Martin}

\section{(2) OpenEdition}

\section{Journals}

Édition électronique

URL : https://journals.openedition.org/e-migrinter/842

DOI : $10.4000 /$ e-migrinter.842

ISSN : 1961-9685

Éditeur

UMR 7301 - Migrinter

Référence électronique

Nelly Martin, « Portrait de Nelly Martin, géomaticienne, bureau 014 », e-Migrinter [En ligne], 15 | 2017, mis en ligne le, consulté le 20 mai 2021. URL : http://journals.openedition.org/e-migrinter/842 ; DOI https://doi.org/10.4000/e-migrinter.842

Ce document a été généré automatiquement le 20 mai 2021.

Tous droits réservés 


\title{
Portrait de Nelly Martin, géomaticienne, bureau 014
}

\author{
Nelly Martin
}

\section{NOTE DE L'ÉDITEUR}

Ce billet fait partie d'une série de quatre portraits réalisés à partir d'un questionnaire initié par Sarah Przybyl et Julie Lemoux.

Quel est ton poste et depuis combien de temps travailles-tu au laboratoire? Que faisais-tu avant de travailler à Migrinter?

Je suis affectée à Migrinter depuis le $1^{\text {er }}$ avril 2014 en tant qu'ingénieur d'études CNRS, géomaticienne.

Je travaillais précédemment dans des laboratoires de recherche en archéologie, notamment à Bordeaux de 2006 à 2014 et à Alexandrie (Egypte) de 1996 à 2002. J'ai une formation initiale de géomètre, complétée par une licence professionnelle en systèmes d'information géographique (SIG). De plus, je suis titulaire du diplôme de l'université de Poitiers SIGmage (Systèmes d'information géographique et méthodes de l'analyse spatiale) depuis octobre 2016.

Comment définirais-tu ta mission au laboratoire Migrinter?

Ma mission est de produire des cartes, mais plus précisément en utilisant les SIG, donc des données cartographiques géoréférencées, liées à une base de données. J'interviens à la demande des chercheurs dans le cadre de leurs programmes de recherche, pour la constitution et l'harmonisation des données, leur traitement et leur restitution.

Pourrais-tu nous décrire en quelques mots une journée-type?

Il n'y en a pas! Mon cœur de métier est le travail au sein des programmes de recherche, mais bien d'autres activités gravitent autour de cette mission. Je participe à la vie du laboratoire, aux réunions mensuelles, à la commission web. Je conseille les 
étudiants et les doctorants, et je donne un cours de cartographie aux étudiants du Master 2 "Migrations internationales ». Je participe aux réseaux professionnels de mon domaine, comme le réseau MATE-SHS (Méthodes Analyses Terrains Enquête en Sciences Humains et Sociales), qui a réuni près de 70 ingénieurs pendant 4 jours lors d'une action nationale de formation en novembre 2016. Toutes ces activités sont réparties sur l'année, en flux plus ou moins tendu selon les périodes...

Peux-tu nous faire part d'un événement, d'une anecdote ou d'une rencontre qui, au cours de ton expérience à Migrinter, ont marqué ta carrière et/ou ta vision des migrations internationales?

Après avoir travaillé pendant une quinzaine d'années au service des fouilles archéologiques, expérience qui m'a passionnée, je souhaitais changer de domaine, me rapprocher de recherches plus contemporaines, sans toutefois avoir une idée très précise en tête.

En 2004, j'avais candidaté à un poste de cartographe à l'université de Poitiers qui comportait un volet sur la thématique des migrations internationales. Classée deuxième pour une seule place disponible, je n'avais pas intégré le poste, mais l'entretien m'avait laissé un bon souvenir. Une dizaine d'années plus tard, j'ai remarqué un profil offert à la mobilité interne au CNRS et affecté à Migrinter. Après avoir postulé, le laboratoire m'a accueillie en 2014.

As-tu été marquée par un (ou plusieurs) événement en particulier au cours de ta carrière à Migrinter? (évolution de poste, arrivée/départ d'un collègue, changement direction, etc.)

Arrivée depuis peu dans le laboratoire, l'évènement marquant a été le colloque des 30 ans de Migrinter. J'ai plus particulièrement été touchée par deux expositions sur les migrations organisées en marge du colloque à Poitiers. L'originalité des supports m'a permis d'appréhender l'actualité des migrations: Moving Beyong Borders mettait en scène des cartes des parcours migratoires et des dispositifs juridiques, avec animation visuelle et fond sonore, et Atlas local présentait des cartes mentales et subjectives dessinées par des demandeurs d'asile, reproduites et brodées sur des draps blancs.

Pourrais-tu donner trois mots qui définissent Migrinter à tes yeux?

Migration, Poitiers, Recherche

UNE IMAGE ... 


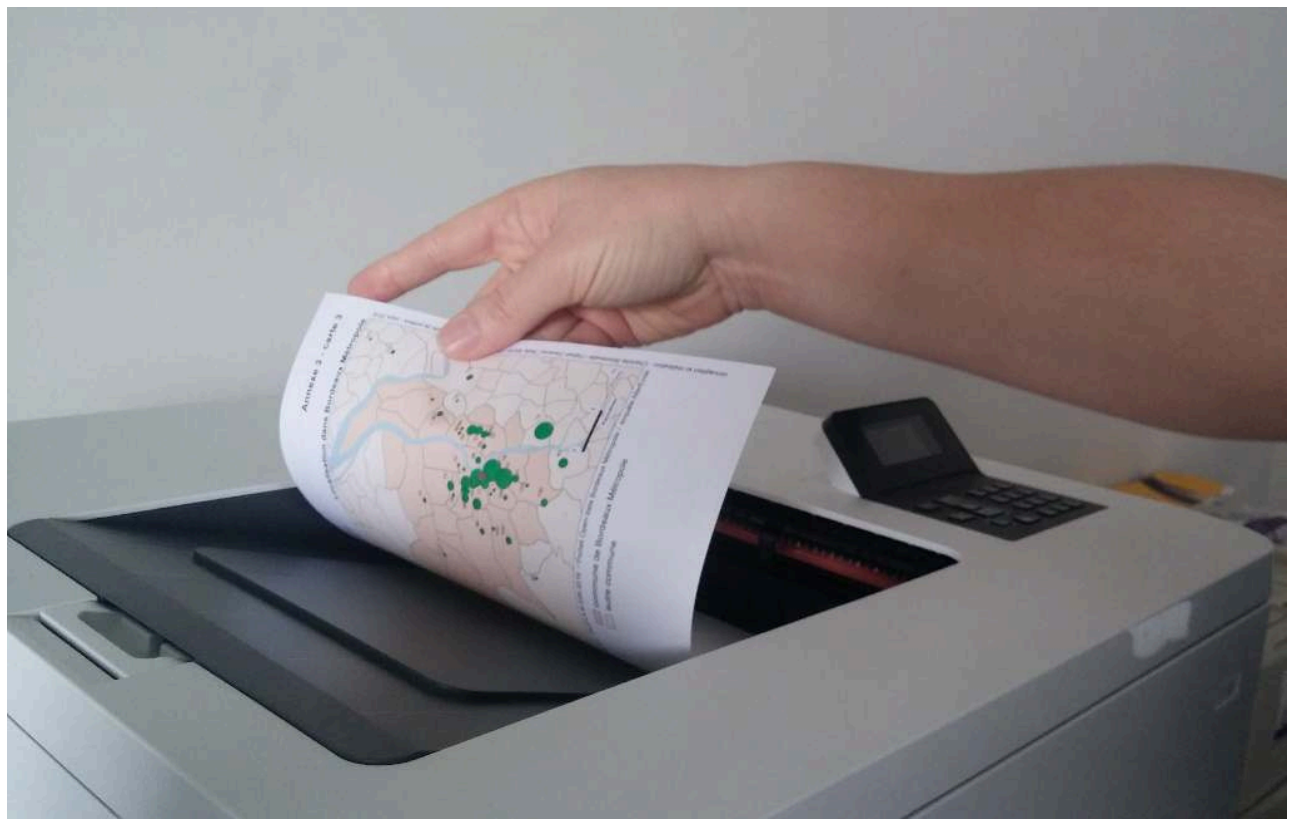

Après divers tâtonnements et discussions, la joie de la carte finalisée, sortant de l'imprimante.

\section{AUTEUR}

\section{NELLY MARTIN}

Ingénieure d'études au CNRS, Migrinter - UMR 7301, CNRS / Université de Poitiers nelly.martin@univ-poitiers.fr 